\title{
Review of Recent Advances in Lipid Analysis of Biological Samples via Ambient Ionization Mass Spectrometry
}

\author{
Haiyan Lu ${ }^{1}$, Hua Zhang ${ }^{1}$, Shuling $\mathrm{Xu}^{1}$ and Lingjun $\mathrm{Li}^{1,2, * \mathbb{D}}$ \\ 1 School of Pharmacy, University of Wisconsin-Madison, Madison, WI 53705, USA; hlu244@wisc.edu (H.L.); \\ hzhang775@wisc.edu (H.Z.); sxu374@wisc.edu (S.X.) \\ 2 Department of Chemistry, University of Wisconsin-Madison, Madison, WI 53706, USA \\ * Correspondence: lingjun.li@wisc.edu; Tel.: +1-608-265-8491
}

Citation: Lu, H.; Zhang, H.; Xu, S.; $\mathrm{Li}$, L. Review of Recent Advances in Lipid Analysis of Biological Samples via Ambient Ionization Mass Spectrometry. Metabolites 2021, 11, 781. https://doi.org/10.3390/ metabo11110781

Academic Editors: Peter Oefner and Zoltan Takats

Received: 17 October 2021

Accepted: 10 November 2021

Published: 15 November 2021

Publisher's Note: MDPI stays neutral with regard to jurisdictional claims in published maps and institutional affiliations.

Copyright: (C) 2021 by the authors Licensee MDPI, Basel, Switzerland. This article is an open access article distributed under the terms and conditions of the Creative Commons Attribution (CC BY) license (https:// creativecommons.org/licenses/by/ $4.0 /)$.
Abstract: The rapid and direct structural characterization of lipids proves to be critical for studying the functional roles of lipids in many biological processes. Among numerous analytical techniques, ambient ionization mass spectrometry (AIMS) allows for a direct molecular characterization of lipids from various complex biological samples with no/minimal sample pretreatment. Over the recent years, researchers have expanded the applications of the AIMS techniques to lipid structural elucidation via a combination with a series of derivatization strategies (e.g., the Paternò-Büchi $(\mathrm{PB})$ reaction, ozone-induced dissociation (OzID), and epoxidation reaction), including carboncarbon double bond $(\mathrm{C}=\mathrm{C})$ locations and sn-positions isomers. Herein, this review summarizes the reaction mechanisms of various derivatization strategies for $\mathrm{C}=\mathrm{C}$ bond analysis, typical instrumental setup, and applications of AIMS in the structural elucidation of lipids from various biological samples (e.g., tissues, cells, and biofluids). In addition, future directions of AIMS for lipid structural elucidation are discussed.

Keywords: lipidomics; structural elucidation; ambient ionization mass spectrometry; biological samples

\section{Introduction}

Lipids are essential biomolecules involved in various cellular functions, including structural components, energy reservoirs, and signal molecules in biological systems [1,2]. Unsaturated lipids, as a subclass of lipids, structurally differ in the types of headgroups (such as phosphatidic acids (PA), phosphatidylcholine (PC), phosphatidylethanolamine (PE), phosphatidylglycerol (PG), phosphatidylinositol (PI), and phosphatidylserine (PS)), carbon-carbon double bond $(\mathrm{C}=\mathrm{C})$ locations, numbers, as well as cis/trans geometric isomerism, and the sn-position of the fatty acyl chain (Figure 1A), which complicate structural characterization [3,4]. In particular, the biological functions of lipids highly depend on their structural diversity and varying expression levels [5]. For example, the unsaturation level of lipids affects cell physiological properties (e.g., the permeability and fluidity of the cell membrane, cardiolipin remodeling, and neurotransmitter release) [6,7]. Metabolic dysregulations of lipids $\mathrm{C}=\mathrm{C}$ bond positional isomers, as well as sn-positions, may be related to many diseases, such as cancers, type II diabetes (T2D), Alzheimer's, and other neurodegenerative diseases [8-11]. Therefore, precise lipid structural elucidation in complex biological samples is of great significance for studying the fundamental mechanism of lipid metabolism and the pathogenesis of various diseases [7].

Mass spectrometry (MS) is widely used for the identification and quantitation of lipids from biological samples with a high sensitivity and specificity [12-14]. Generally, tandem mass spectrometry (MS/MS) via the collision-induced desorption (CID) method can provide a lipid head group and fatty acyl chain composition, but has limited application in directly locating the $\mathrm{C}=\mathrm{C}$ positions, because low energy $\mathrm{CID}$ cannot obtain informative fragment ions to assign the $\mathrm{C}=\mathrm{C}$ location [15-17]. Hence, emerging MS-based dissociation 
methods, including ozone-induced dissociation (OzID) [18,19], electron-induced dissociation (EID) [20], ultraviolet photodissociation (UVPD) $[1,21]$, and selective $\mathrm{C}=\mathrm{C}$ bond derivatization methods (e.g., the Paternò-Büchi (PB) reaction [22,23], meta-chloroperoxybenzoic acid ( $m$-CPBA) epoxidation [24,25], and peracetic acid (PAA) epoxidation [5]), have been developed to elucidate the lipid structure. Traditionally, MS coupled with chromatographic approaches (such as liquid chromatography (LC)) are effective tools for the characterization of lipid isomers [26-28], but these methods usually require tedious sample preparations prior to MS analysis. Compared with traditional MS approaches, ambient ionization mass spectrometry (AIMS) techniques allow for the rapid and direct analysis of lipids from raw complex biological samples with minimal or no sample treatments [29].

A

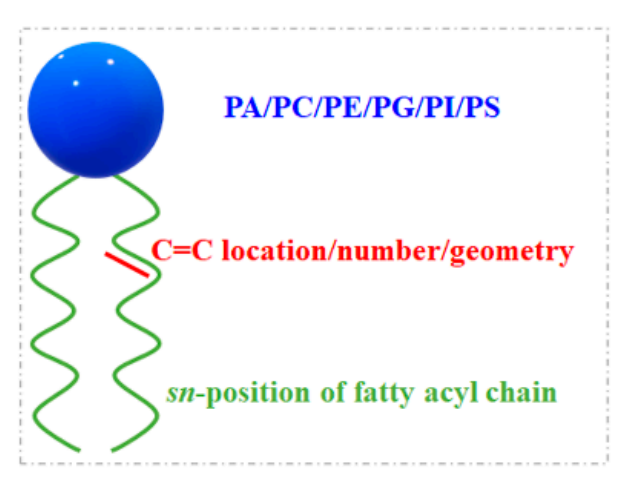

B

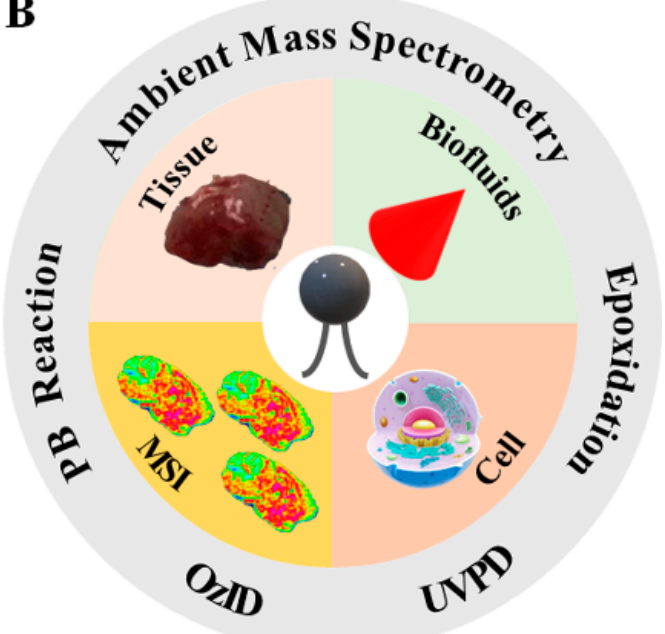

Figure 1. (A) The schematic figure indicates the chemical structure diversity and complexity of unsaturated lipids; (B) representation of different derivatization strategies coupling of AIMS techniques (outer ring) and examples of their applications (central pie chart).

For example, lipids from various human cancerous tissue samples have been directly characterized by AIMS techniques, including desorption electrospray ionization mass spectrometry (DESI-MS) [30], rapid evaporative ionization mass spectrometry (REIMS) [31], MasSpec Pen [32], and internal extractive electrospray ionization mass spectrometry (iEESIMS) [33,34]. Atmospheric pressure matrix-assisted laser/desorption ionization mass spectrometry (AP-MALDI-MS) is an alternative AIMS technique that enables the obtaining of high spatial resolution images of lipids in the brain at an atmospheric pressure condition [35]. Compared with conventional vacuum matrix-assisted laser desorption/ionization mass spectrometry (MALDI-MS) [36,37], AP-MALDI-MS significantly increases the ease of sample preparation [38,39]. The significant difference between AIMS techniques and the conventional high vacuum MALDI-MS is that AIMS techniques offer minimal sample preparation and effectively eliminate the matrix-associated limitations with no need of using the exogenous matrix compound [40]. Taken together, these studies laid a solid foundation for the applications of AIMS techniques in advanced lipidomic research. Therefore, a series of AIMS techniques have been developed with expanded applications in lipid structural elucidation (including $C=C$ locations and sn-positions) over the past few years. Herein, this review summarizes the mechanisms of various derivatization strategies for $\mathrm{C}=\mathrm{C}$ location analysis, typical instrumental setup, and applications of AIMS in the structural elucidation of lipids from various biological samples within the past five years. The applications of AIMS techniques coupling with different derivatization strategies in the lipid structural elucidation in this review are illustrated in Figure 1B. 


\section{Mechanism and Instrumental Setup of Various Strategies for Lipid Structural Elucidation}

Numerous AIMS techniques have been applied for the characterization of $\mathrm{C}=\mathrm{C}$ locations, as well as sn-positions, in unsaturated lipids via combining with different types of derivatization strategies, including (1) PB reaction, (2) OzID and UVPD, (3) epoxidation reaction and (4) other strategies. In this section, both the mechanism between various derivatization strategies and $\mathrm{C}=\mathrm{C}$ bond analysis and the typical instrumental setup of AIMS techniques coupled with different derivatization strategies for lipid structural elucidation will be introduced and discussed.

\subsection{PB Reaction}

The $\mathrm{PB}$ reaction is a classic [2+2] photochemical reaction and is widely used for the formation of oxetane ring compounds in organic synthesis [41]. The PB reaction has gained attention for lipid structural elucidation, since its coupling to tandem MS (PB-MS/MS) analysis can result in $\mathrm{C}=\mathrm{C}$ positional information in unsaturated lipids [42,43]. To clearly describe the reaction mechanism of the $\mathrm{PB}$ reaction with the $\mathrm{C}=\mathrm{C}$ bond, acetone as a $\mathrm{PB}$ reagent is taken as an example. As shown in Figure 2, for each lipid $\mathrm{C}=\mathrm{C}$ location isomer, two regioisomers of the PB products (with 58 Da mass shift from the original unsaturated lipids) could form, owing to two possible orientations for the addition of acetone to a $\mathrm{C}=\mathrm{C}$ bond, thereby generating a pair of diagnostic ions that can be used for assigning (Figure 2A) and quantifying (Figure $2 \mathrm{~B}$ ) the $\mathrm{C}=\mathrm{C}$ location isomers of unsaturated lipids [16]. Despite great progress being reported in using acetone as a derivatization reagent in the $\mathrm{PB}$ reaction, other $\mathrm{PB}$ reagents (e.g., benzophenone [44], 2-acetylpyridine (2-AP) [26], and 2', $4^{\prime}, 6^{\prime}$-trifluoroacetophenone (triFAP) [45]) have been developed for the study of unsaturated lipids. It has been noted that the specific mass shift of PB products is related with the PB reagents mass. PB-MS/MS have several notable features, including the fact that (1) the specific mass increase from the original unsaturated lipids can be readily used for the identification of PB products, (2) the diagnostic ions derived from the PB products enable confident identifications of the $C=C$ location isomers, (3) the ion intensities of diagnostic ions could be used for the quantitative analysis of lipid $\mathrm{C}=\mathrm{C}$ location isomers, and (4) there is a simple experimental setup for the reaction, and no need for MS instrument modification. With these advantages, there have been some derivatization methods based on the $\mathrm{PB}$ reaction. For example, a double derivatization strategy, which utilized both an acetone labeling of the $\mathrm{C}=\mathrm{C}$ bond via the $\mathrm{PB}$ reaction in order to provide diagnostic ions for pinpointing the $\mathrm{C}=\mathrm{C}$ locations and a $N, N$-diethyl-1,2-ethanediamine (DEEA) labeling of the carboxyl group in order to improve the MS response of diagnostic ions, was developed for the sensitivity localization of the $\mathrm{C}=\mathrm{C}$ bond in free fatty acids (FFAs) [46].

Additionally, to allow the $\mathrm{PB}$ reaction to be available for the characterization of $\mathrm{C}=\mathrm{C}$ locations in unsaturated lipids from broad types of samples, different sampling methods have been proposed. For instance, a polymer coating transfer enrichment (PCTE) method coupled with the PB reaction was developed for a nanoelectrospray ionization mass spectrometry (PCTE-PB-nanoESI-MS) analysis of unsaturated lipids in human biofluid samples [48]. Similarly, the in vivo and microscale profiling of lipid $C=C$ location isomers in biological tissues has been realized by combining the $\mathrm{PB}$ reaction with surfacecoated probe nanoESI-MS (SCP-PB-nanoESI-MS) [47]. In SCP-PB-nanoESI-MS analysis (Figure 2C), a biocompatible SPEM probe with a nanospray tip was used for the extraction and ionization of lipids from a biological tissue sample, and then the solvent containing the PB regents was used to desorb lipids enriched on the SPEM probe. Subsequently, the $\mathrm{PB}$ reaction was triggered by irradiation with an UV light at $254 \mathrm{~nm}$. After that, the high voltage was applied on the SPEM probe for nanoESI-MS/MS and generated diagnostic ions corresponding to the location of the $\mathrm{C}=\mathrm{C}$ bond. 

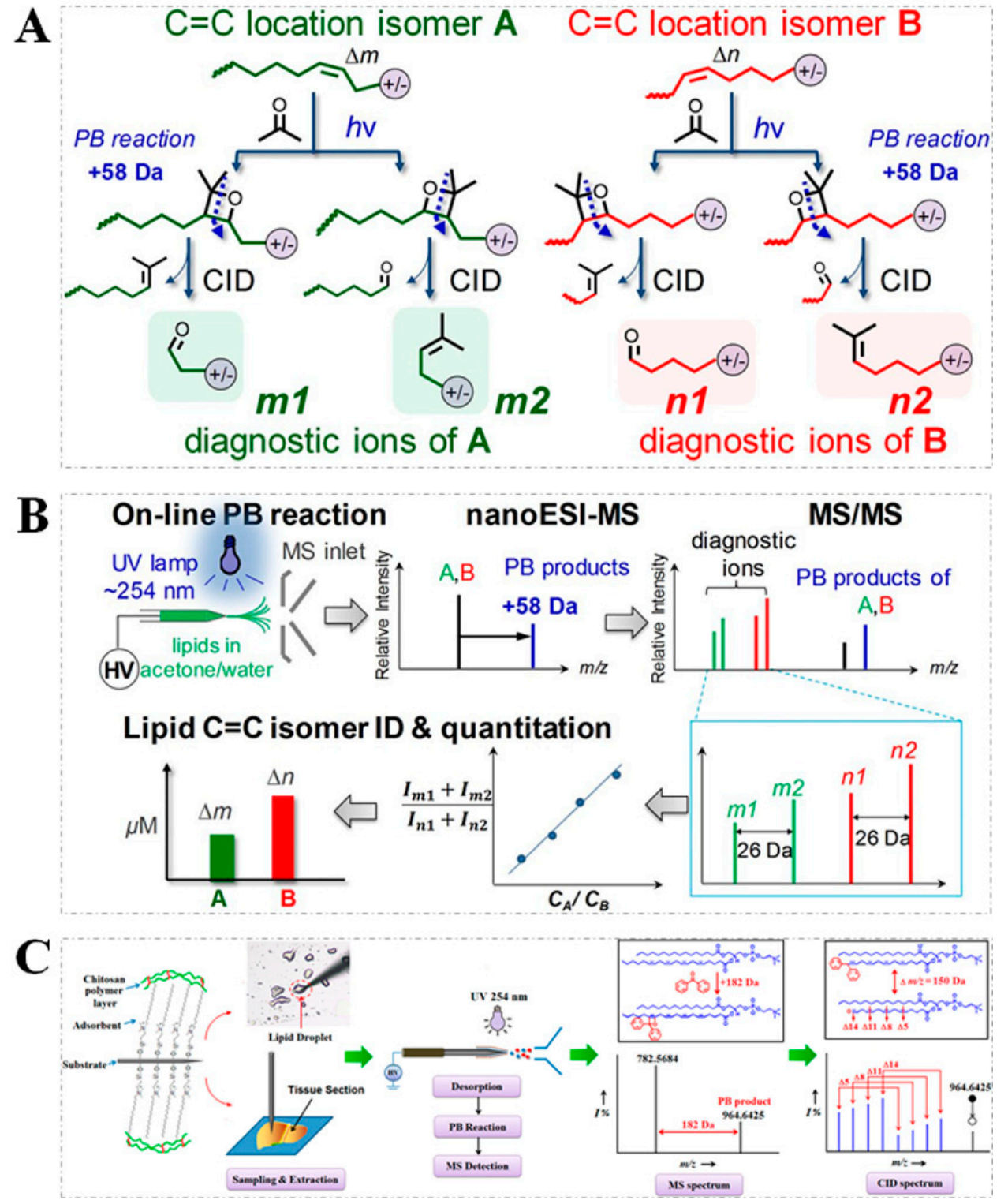

Figure 2. (A) The formation mechanism of $\mathrm{C}=\mathrm{C}$ diagnostic ions from lipid $\mathrm{C}=\mathrm{C}$ location isomers via $\mathrm{PB}$ reaction; $(\mathrm{B})$ the workflow of direct characterization and quantitation of lipid $\mathrm{C}=\mathrm{C}$ location isomers by $\mathrm{PB}--$ nanoESI-MS/MS (note: Figure 2A,B reproduced from Ref. [16] with permission from National Academy of Sciences); (C) the workflow of SCP-PB-nanoESI-MS method for in vivo and microscale profiling of lipid characterization in tissue sections (reproduced permission from Ref. [47]. Copyright (2019) American Chemical Society).

\subsection{OzID and UVPD}

OzID is an ion activation method that exploits the gas-phase reaction between massselected unsaturated lipid ions and ozone, which could selectively cleave the $\mathrm{C}=\mathrm{C}$ bond located on the acyl chains, thereby generating diagnostic fragment ions (such as aldehyde and Criegee ions) to assign sites of the $\mathrm{C}=\mathrm{C}$ bond in unsaturated lipids. Taking GPCho (16:0/9Z-18:1) as an example, the mechanism of OzID with unsaturated lipid ions in an ion trap mass spectrometer was shown in Figure 3. The mass-selected sodium adduct ion of GPCho (16:0/9Z-18:1) at $m / z 782$ could produce primary and secondary ozonide under the presence of ozone, and could then generate two product ions at $m / z 672$ and $m / z 688$ corresponding to aldehyde and Criegee ions, which were used for the identification of $\mathrm{C}=\mathrm{C}$ positions, caused by a neutral loss of $110 \mathrm{Da}$ and $94 \mathrm{Da}$ from primary ozonide under CID analysis, respectively [49]. Additionally, UVPD, as a high-energy photoactivation 
method, could provide informative lipid structural information, which has been used for the analysis of different classes of lipids, either as a standalone MS/MS strategy or in conjunction with a collisional activation approach to develop hybrid $\mathrm{MS}^{\mathrm{n}}$ strategies. In essence, UVPD allows for the identification of $C=C$ locations based on characteristic diagnostic ions with $24 \mathrm{Da}$ mass differences resulting from the cleavage of carbon-carbon bonds adjacent to the $\mathrm{C}=\mathrm{C}$ bond $[21,50-52]$. Both OzID and UVPD are of great potential for lipid structural analysis, but they often require special instrument modification.

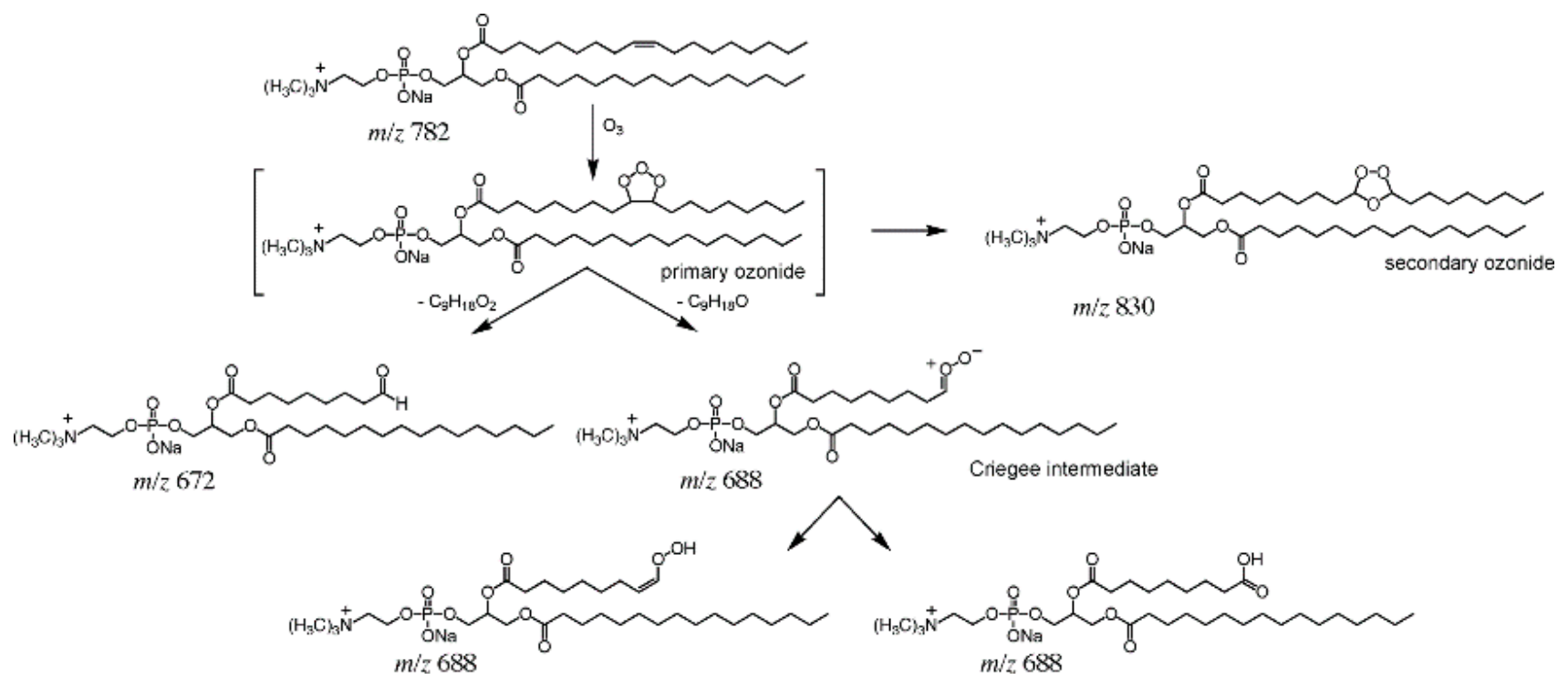

Figure 3. The reaction mechanism of OzID with mass-selected [GPCho $(16: 0 / 9 \mathrm{Z}-18: 1)+\mathrm{Na}]^{+}$ions $(m / z$ 782) in ion trap mass spectrometer (Reproduced permission from Ref. [49]. Copyright (2008) American Chemical Society).

\subsection{Epoxidation Reaction}

The epoxidation reaction is another chemical derivatization strategy for the structural determination of lipids. Epoxidation using either meta-chloroperoxybenzoic acid $(\mathrm{m}$ CPBA) (Figure 4A) [24] or peracetic acid (PAA) (Figure 4B) [5] coupled with CID-MS/MS to produce a diagnostic ion pair, as shown in Figure 4. Briefly, unsaturated lipids are firstly oxidized via $m$-CPBA or PAA to generate an epoxide; then, the epoxide product is isolated for CID-MS/MS analysis, which generates a pair of diagnostic ions for pinpointing the $\mathrm{C}=\mathrm{C}$ bond location $[24,25]$. PAA epoxidation can be combined with nanoESI-MS/MS for assigning the $C=C$ bond in fatty acids (FAs) from the solution (Figure $4 C$ ). The method attained satisfactory linearity in a quantitative analysis of $\mathrm{C}=\mathrm{C}$ bond positional FA isomers (including FA 16:1 (9Z), FA 18:1 (9Z), and FA 18:1 (11Z)) ( $\left.\mathrm{R}^{2}>0.9989\right)$, the limit of detections (LODs) and relative standard deviations (RSDs) for three tested FAs were $4.2 \mathrm{nM}-5.6 \mathrm{nM}$ and $3.4-8.9 \%$, respectively. Furthermore, PAA epoxidation can be combined with matrixassisted laser desorption/ionization time-of-fight/time-of-fight MS (MALDI-TOF/TOFMS) for the spatial mapping and characterization of the $C=C$ bond in FAs from tissue sections (Figure 4D) [5]. Although epoxidation reactions by both $m$-CPBA and PAA have been developed for the analysis of unsaturated lipids, PAA offers the advantage of an easy sample clean-up, owing to the high volatility of PAA, and PAA presents minimal potential side effects, such as ion suppression and MALDI matrix oxidization, during ontissue epoxidation [5]. Recently, chloroauric acid $\left(\mathrm{HAuCl}_{4}\right)$ was added into an electrospray solvent during microdroplet mass spectrometry analysis; the resulting oxidation products could be used to identify the location of one or more $C=C$ bonds in unsaturated lipids. The mechanism of this method involved $\mathrm{C}=\mathrm{C}$ bond epoxidation, followed by the formation of the final products [53]. 


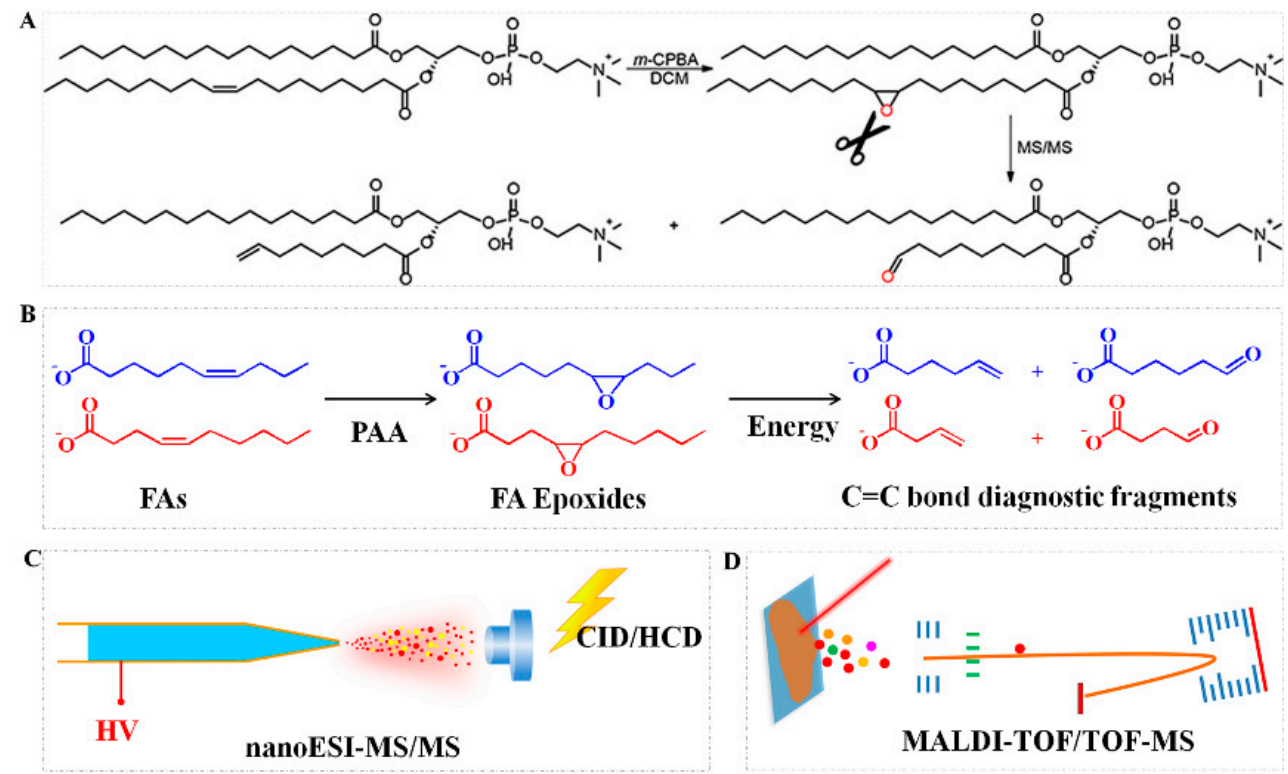

Figure 4. The mechanism of epoxidation reaction induced by $m-$ CPBA (A) (reproduced permission from Ref. [24]. Copyright (2019) American Chemical Society.) and PAA (B) to produce diagnostic fragment ion pair. The workflow of PAA epoxidation in combination with nanoESI-MS/MS (C) for assigning $\mathrm{C}=\mathrm{C}$ bond in FAs from solution and MALDI-TOF/TOF-MS (D) for spatial characterization of $C=C$ bond in FAs from tissue sections (note: Figure 4B-D, reproduced from Ref. [5] with permission from the Royal Society of Chemistry).

\subsection{Other Strategies}

In addition to the $\mathrm{PB}$ reaction, OzID, UVPD, and epoxidation derivatization using $m$-CPBA, PAA, as well as $\mathrm{HAuCl}_{4}$, plasma, and electrochemical-induced epoxidations were also developed in the structural lipidomic study. For instance, the $\mathrm{C}=\mathrm{C}$ bond can be oxidized and cleaved under the low-temperature plasma (LTP) condition, and the generated fragment ions can be used to assign $\mathrm{C}=\mathrm{C}$ positions. In LTP-induced epoxidation, air was used as the oxidizing agent, with no need for other special solvents [54]. Moreover, the LTP probe enabled the online epoxidation and rapid analysis of the monounsaturated, and polyunsaturated FAs on paper-based analytical devices (PADs) within $2 \mathrm{~s}$ (Figure 5A) [55]. In this workflow, when the paper strip containing the unsaturated FAs solution was placed between a LTP probe and the MS ion source inlet, the epoxidation reaction was promptly initiated, and then the epoxidation product was immediately ionized and detected by MS when the paper strip was in touch with the MS ion source inlet. NanoESI-MS, as the variant of traditional ESI-MS, offers a special advantage of ESI-MS in the analysis of a broad range of biomolecules with low sample consumption [56,57]. An on-demand electrochemical epoxidation coupled with a nanoESI-MS strategy was developed to locate the $\mathrm{C}=\mathrm{C}$ bond position in lipids [58]. In this workflow, the onset of the electro-epoxidation of the $\mathrm{C}=\mathrm{C}$ bond could be controlled by tuning the voltage, and the diagnostic ions derived from the fragmentation of electro-epoxidized products by MS/MS were used to indicate the $\mathrm{C}=\mathrm{C}$ positions. To circumvent the challenge in spatially resolving positional isomers in lipidomic analyses, the method for the online selective photochemical derivatization of the $\mathrm{C}=\mathrm{C}$ bond by singlet oxygen $\left({ }^{1} \mathrm{O}_{2}\right)$ was proposed [2]. The mechanism of $\mathrm{C}=\mathrm{C}$ bond oxidation by ${ }^{1} \mathrm{O}_{2}$ (Figure $5 \mathrm{~B}$ ) can be briefly descripted as follows. ${ }^{1} \mathrm{O}_{2}$ generated under a photosensitizer interacts with unsaturated lipids to form lipid hydroperoxides (LOOHs), where the cleavage of LOOHs at the location of the hydroperoxide group in $\mathrm{CID}$ analysis indicates the $\mathrm{C}=\mathrm{C}$ locations. Nanospray desorption electrospray ionization mass spectrometry (nano-DESI-MS), as a variant of DESI-MS, showed its advantages in the high-efficiency extraction and quantitative determination of phospholipids $[59,60]$. Figure $5 \mathrm{C}$ shows the experimental setup of the online ${ }^{1} \mathrm{O}_{2}$ derivatization of the $\mathrm{C}=\mathrm{C}$ bond 
combined with nano-DESI-MS. Moreover, a combined approach of cryogenic gas-phase infrared spectroscopy, ion mobility-mass spectrometry (IM-MS), and quantum chemical calculations for the investigation of the $C=C$ positional in FAs isomers was implemented by a non-covalent formation without chemical treatments or instruments modifications [61].

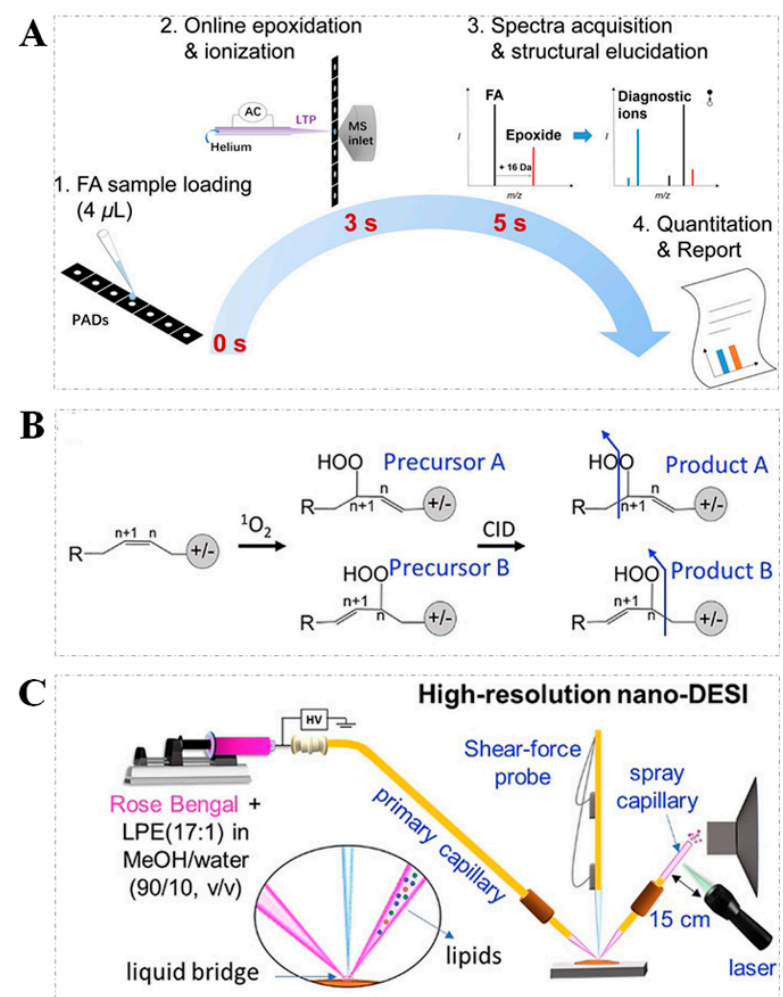

Figure 5. (A) The workflow of online epoxidation/ionization of unsaturated FAs on paper strips by LTP-MS (reproduced permission from Ref. [55]. Copyright (2018) American Chemical Society); (B) the mechanism of $\mathrm{C}=\mathrm{C}$ bond oxidation by ${ }^{1} \mathrm{O}_{2}$ and fragmentation via $\mathrm{CID}$ to yield products; (C) the experimental setup of online ${ }^{1} \mathrm{O}_{2}$ derivatization of $\mathrm{C}=\mathrm{C}$ bond combined with nano-DESI-MS (note: Figure 5B,C, reproduced from Ref. with permission from permission of Wiley-VCH GmbH).

In summary, among the above-mentioned derivatization methods (such as the PB reaction, OzID, UVPD, epoxidation by $m$-CPBA, $\mathrm{PAA}$ and $\mathrm{HAuCl}_{4}$, plasma oxidation, electrochemical epoxidation, and ${ }^{1} \mathrm{O}_{2}$ ), the $\mathrm{PB}$ reaction is the most classic photochemical strategy used for pinpointing $\mathrm{C}=\mathrm{C}$ location isomers of unsaturated lipids in both shotgun analysis [16,23] and high-performance liquid chromatography-tandem mass spectrometry (HPLC-MS/MS) $[7,8,45]$ workflow. UVPD can locate $C=C$ positions and sn-specific fatty acyls, whereas OzID has been reported for locating $C=C$ positions and is used primarily for the sodium-adducted lipids in shotgun-based lipidomics [62,63]. The common concern for the PB reaction, OzID, and UVPD is that the use of UV light/ozone in these reactions might pose unexpected potential health risks $[3,64]$. Unlike the PB reaction, UVPD, and OzID, the epoxidation reaction induced by $m$-CPBA, PAA, and $\mathrm{HAuCl}_{4}$ offers a much higher specificity and occurs under ambient conditions without UV irradiation or hardware modification [65]. For LTP oxidation and on-demand electrochemical epoxidation, they provide alternative approaches to determine $\mathrm{C}=\mathrm{C}$ locations without explicit chemical derivatization or sample treatment prior to MS detection, which might hold potential for high-throughput lipid structural elucidation.

\section{The Applications of AIMS in Lipid Structural Elucidation}

The $C=C$ location, sn-position, and branched chain isomers in unsaturated lipids have an important influence on their biological functions. Therefore, precise lipid structural characterization is critical for in-depth lipidomic investigation. In this section, we introduce 
the applications of AIMS techniques in the structural elucidation of lipids from different types of biological samples (e.g., tissues, biofluids, and cells) within the past five years.

\subsection{Direct Characterization of Unsaturated Lipid Isomers in Tissue Samples}

A tissue specimen is one of the most common biological samples for both clinical and laboratory study; in particular, the fine structure characterization of unsaturated lipids in tissue samples plays a critical role in disease molecular diagnosis [66]. The PB reaction, as a typical photochemical derivatization method, has been coupled with AIMS techniques for the direct characterization of the $\mathrm{C}=\mathrm{C}$ location in tissue samples. For example, online $\mathrm{PB}$ reaction coupling with nanoESI-MS/MS enabled the identification of 96 unsaturated FAs and glycerophospholipids (GPs) from rat brain tissue, and the relative quantitation of $\mathrm{C}=\mathrm{C}$ positional isomers in FAs with chain lengths ranging from 16 to 22 carbons. Based on the intensities of the diagnostic ion, the relative abundances of $\triangle 11 \mathrm{C}=\mathrm{C}$ location isomers from FA (18:1), PC (18:0-18:1), and PC (18:1-18:1) between normal and cancerous mouse breast tissues were compared, offering a new perspective for the precise molecular diagnosis of malignancies [16].

In addition, an in situ lipid extraction and ionization AIMS technique by combining the $\mathrm{PB}$ reaction with a liquid microjunction surface sampling probe (LMJ-SSP) (Figure 6A) was developed for the identification and quantitation of lipid C $=\mathrm{C}$ location isomers [67], with fast analysis $(<2 \mathrm{~min}$ ), good reproducibility ( $\mathrm{RSD}<10 \%$ ), and a satisfactory linear relationship $\left(R^{2}=0.999\right)$. By exploiting this method, unsaturated lipid $C=C$ bond isomers in the tissue sections of the rat brain, lung, liver, spleen, and kidney were rapidly profiled, showing great potential in rapid tissue analysis and clinical molecular diagnosis. As an example, a biopsy-type sampling method combined with the PB reaction was used for the direct sampling and analysis of lipids from rat organs (including the brain, kidney, and liver) (with an area of approximately $0.008 \mathrm{~cm}^{2}$ for each analysis) (Figure 6B) [68]. A total of 15 unsaturated FAs and 31 unsaturated phospholipids, including phosphatidylserines (PSs), phosphatidylglycerols (PGs), phosphatidylinositols (PIs), phosphatidylethanolamines (PEs), phosphatidic acids (PAs), lyso-PAs (LPAs), and lyso-PGs (LPGs), were successfully identified. Furthermore, investigations of lipid compositions and $\mathrm{C}=\mathrm{C}$ location isomers from human intestinal tissue and zebrafish were successfully accomplished through SCP-PB-nanoESI-MS [47].

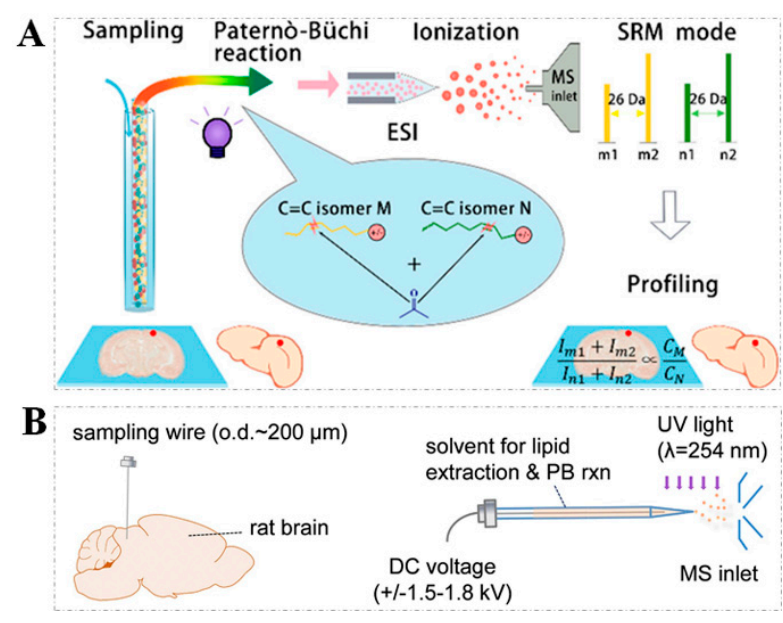

Figure 6. The application examples of typical AIMS techniques in pinpointing $\mathrm{C}=\mathrm{C}$ locations via $\mathrm{PB}$ reaction. (A) Direct sampling of tissue section by LMJ-SSP (reproduced permission from Ref. [67]. Copyright (2018) American Chemical Society); (B) tissue sampling by a stainless-steel wire (reproduced from Ref. [68] with permission from Elsevier B.V.).

Lipids have a substantial influence on vertebrate embryogenesis. The large-scale and spatiotemporal monitoring of unsaturated lipids with $\mathrm{C}=\mathrm{C}$ bond specificity in zebrafish embryos has been achieved by PB-nanoESI-MS/MS [69]. The findings indicated that the lipid isomer composition remained to be stable in yolk throughout embryogenesis, while 
obvious alterations in the ratios of $\mathrm{C}=\mathrm{C}$ location and fatty acyl composition isomers for some lipids were revealed between blastomeres and yolk from the zygote to $4 \mathrm{~h}$ postfertilization. Moreover, the double derivatization strategy based on the PB reaction has enabled the assignment of the $\mathrm{C}=\mathrm{C}$ locations of FFAs from nonalcoholic fatty liver disease (NAFLD) mouse model and control mouse liver samples [46]. Infrared matrix-assisted laser desorption electrospray ionization (IR-MALDESI), as a hybrid soft ionization source based on IR-laser desorption followed by electrospray post-ionization, has been combined with on-tissue $m$-CPBA epoxidation for the in situ detection of $\mathrm{FAs} C=\mathrm{C}$ positional isomers in rat liver and human bladder cancer tissue [65]. Furthermore, when coupling the ${ }^{1} \mathrm{O}_{2}$ reaction with nano-DESI-MS, several isomeric lipids from mouse muscle and uterine tissues were directly detected [2]. Recently, an online coupling of the PB reaction and radical-direct fragmentation with in-capillary extraction nanoelectrospray ionization mass spectrometry (ICE-nanoESI-MS) [70] was developed in order to determine $\mathrm{C}=\mathrm{C}$ locations and stereospecific numbering positions of potential lipid biomarkers for human colorectal cancer under an ambient condition; the results indicated that lysophospholipids could act as potential biomarkers related to the pathogenesis of human colorectal cancer. In short, these results confirmed that AIMS, combined with derivatization methods, could successfully detect the molecular variations in unsaturated lipid isomers within tissue samples, showing the potential capability in providing deeper insights into the processes resulting from an altered unsaturated lipid metabolism within complex tissues.

\subsection{Direct Characterization of Unsaturated Lipid Isomers in Biofluid Samples}

Besides tissue samples, AIMS techniques in combination with derivatization strategies are also widely used for lipidomic studies from biofluid samples, such as plasma, blood, and serum. For example, PB-MS/MS enabled the quantitation of unsaturated FAs from blood, and from plasma in a much more rapid manner [71]. Excitingly, the direct MS quantitative and qualitative determination of the lipid structure at the $C=C$ positions level in small volume biofluid samples $(5 \mu \mathrm{L}$ ) has been achieved (Figure 7) by PCTE-PB-nanoESI-MS [48]. Despite the capability of the PCTE-PB-nanoESI-MS method in identifying potential blood biomarkers for T2D being demonstrated, the reproducibility of the quantitation of lipids in the biofluid sample needs to be further improved because the current PCTE procedure still requires a multi-step manual transfer of samples and solvents. The unsaturated lipid oxidation facilitated by LTP has enabled the identification and quantitation of $\mathrm{C}=\mathrm{C}$ locations in FAs within human plasma samples [72]. In a similar manner, locating the $\mathrm{C}=\mathrm{C}$ bond in unsaturated phospholipids (e.g., phosphatidylcholines (PCs), PEs, and phosphatidylinositols (PIs)) from bovine liver extract has been performed [73], which further extended the LTP epoxidation for the analyses of a large variety of phospholipids. Moreover, the LTP probe enabled the online epoxidation and rapid identification of unsaturated FA isomers in human, equine, and fetal bovine serum on PADs within $2 \mathrm{~s}$. The LOD was determined to be $0.1 \mu \mathrm{M}$ for oleic acid. The method shows great potential in point-of-care (POC) clinical diagnosis with fast and high-throughput features [55]. Unlike LTP oxidation, an integrated electrocatalytic nESI-MS platform that utilizes non-inert metal electrodes (e.g., Ir and Ru) has achieved a rapid quantification of FAs isomers from raw serum sample [74].

\subsection{Direct Characterization of Unsaturated Lipid Isomers in Cell Samples}

The cell is the basic unit of living organisms and is responsible for many life processes. Monitoring quantitative changes in metabolites (e.g., FAs and PCs) in cell samples has received increasing attention to facilitate studies in cancer biology $[75,76]$. The quantitative characterization of FAs isomers from complex biological samples has been achieved by using PAA-induced epoxidation coupled with nanoESI-MS, offering a broad utility for various MS platforms. The method enabled confident identifications of 37 monounsaturated FAs with $\mathrm{C}=\mathrm{C}$ bond positions from human cell lines (including HPV16-E6E7 immortalized human pancreatic duct epithelial (HPDE/E6E7) cells and pancreatic cancer cells (PANC-1)) [5]. Additionally, the selective detection of unsaturated FAs from normal 
and cancerous human prostate cells has been realized by PB-MS/MS, enabling a better understanding of the role of the FA isomers in the development of human prostate cancer [71]. In recent years, single cell analysis has attracted increasing attention, with a capability to allow for the study of cell-to-cell heterogeneity and to facilitate novel biomarker discovery [77]. A simple single cell mass spectrometry (SCMS) technique combined with the $\mathrm{PB}$ reaction was developed [6], and achieved the determination of $\mathrm{C}=\mathrm{C}$ locations in unsaturated lipids at the single-cell level, showing the potential utility for other reactive SCMS studies of the molecular characterization of unsaturated lipids in single cells.
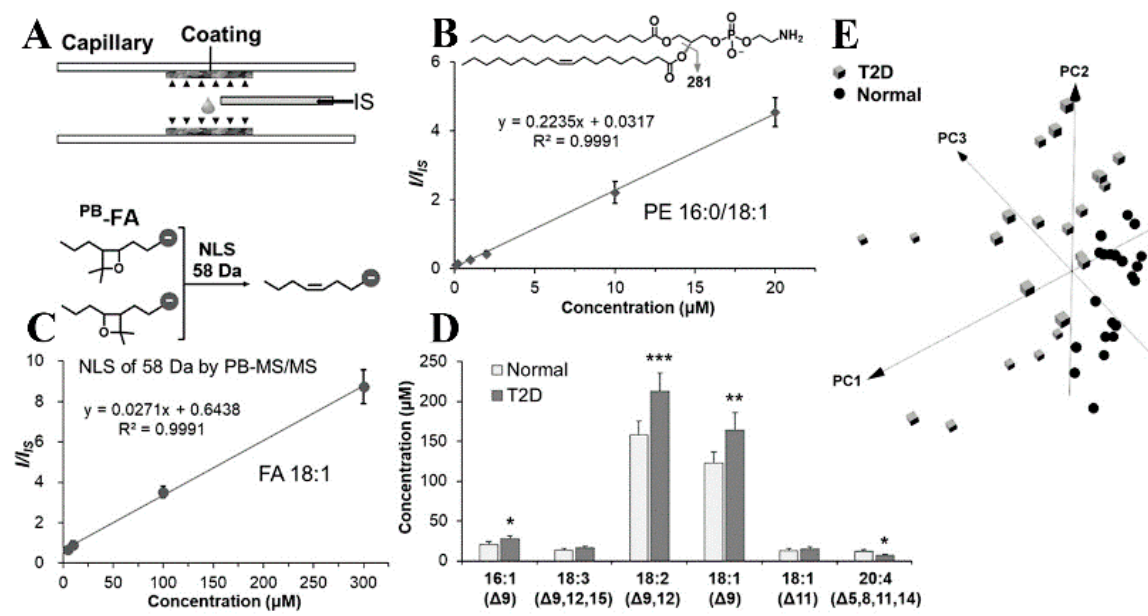

Figure 7. Quantitation of lipids in biofluid samples by PCTE-PB-nanoESI-MS (reproduced from Ref. [48] with permission from Wiley-VCH Verlag GmbH \& Co. KGaA, Weinheim). (A) Incorporation of internal standards by polymer coating; (B) calibration curve of PE 16:0/18:1; (C) calibration curve of FA 18:1. Inset shows the fragmentation of derivatized FAs; (D) comparison of absolute concentration of some major free FAs in normal and T2D blood samples; (E) 3D PCA plot of the data of major free FAs in normal and T2D blood samples. (Note: neutral loss scan (NLS), type 2 diabetes (T2D), ${ }^{*} p<0.05,{ }^{* *} p<0.01,{ }^{* * *} p<0.001$, Student's $t$-test).

\subsection{Spatial Visualization of Unsaturated Lipid Isomers within Tissue Sections}

Mass spectrometry imaging (MSI) allows for the molecularly mapping of the spatial distribution of compounds over the sample, and provides multiplexed information without the need for labeling or staining, which has emerged as a promising technique in many areas (e.g., biomedical science, food science, and forensics) [78-81]. Traditionally, MSI often reflects the summed distribution of multiple isomeric molecules. Nevertheless, characterizing lipids only at the sum of the compositional level easily neglects lipid isomeric heterogeneity [18,82]. In general, matrix-assisted laser desorption ionization mass spectrometry imaging (MALDI-MSI) shows an excellent performance in the visualization of the spatial distribution of phospholipids and glycolipids, but the information of $\mathrm{C}=\mathrm{C}$ location isomers cannot be acquired. To better obtain the information of $\mathrm{C}=\mathrm{C}$ location isomers, some chemical derivatization methods were combined with MALDI-MSI. For instance, the PB reaction coupled with MALDI-MSI was used for the localization of the $\mathrm{C}=\mathrm{C}$ bond in phospholipids and glycolipids within tissue samples, which provides a novel tool for investigating the biological roles of lipid isomers [83]. As a significant advance in capabilities for isomer-resolved MSI lipidomics, the recent study reported an implementation of isomer-resolved MALDI-MSI on a SYNAPT HDMS G2-Si quadrupole time-of-flight (Q-TOF) mass spectrometer, allowing for fast OzID for the imaging of both the $\mathrm{C}=\mathrm{C}$ bond and sn-positional isomers in tissue samples [84]. Additionally, combining MALDI-MSI with OzID demonstrated that both the $\mathrm{C}=\mathrm{C}$ bond and sn-positional isomeric lipids differed in spatial locations within mouse brain tissue sections [18]. On-tissue ozonization combined with MALDI-MSI enabled the imaging of the differential distribution of phospholipids with $\mathrm{C}=\mathrm{C}$ bond positional isomers in tissue sections of mouse brain and human colon [85]. Simi- 
larly, by using $N, N, N$-trimethyl-2-(piperazin-1-yl)ethan-1-aminium iodide (TMPA), 20 FAs were successfully imaged in rat kidney and brain tissues by MALDI-MSI [86]. Furthermore, the performance of on-tissue PAA epoxidation combined with a MALDI-TOF/TOF-MS platform to map the spatial distribution of FA isomers within tumor tissue sections from a murine melanoma model has been confirmed (Figure 8A) [5]. The results provide evidence that the on-tissue epoxidation reaction coupled with the MALDI-TOF/TOF-MS platform could provide a high precision spatial distribution of FA isomers from complex tissue samples.

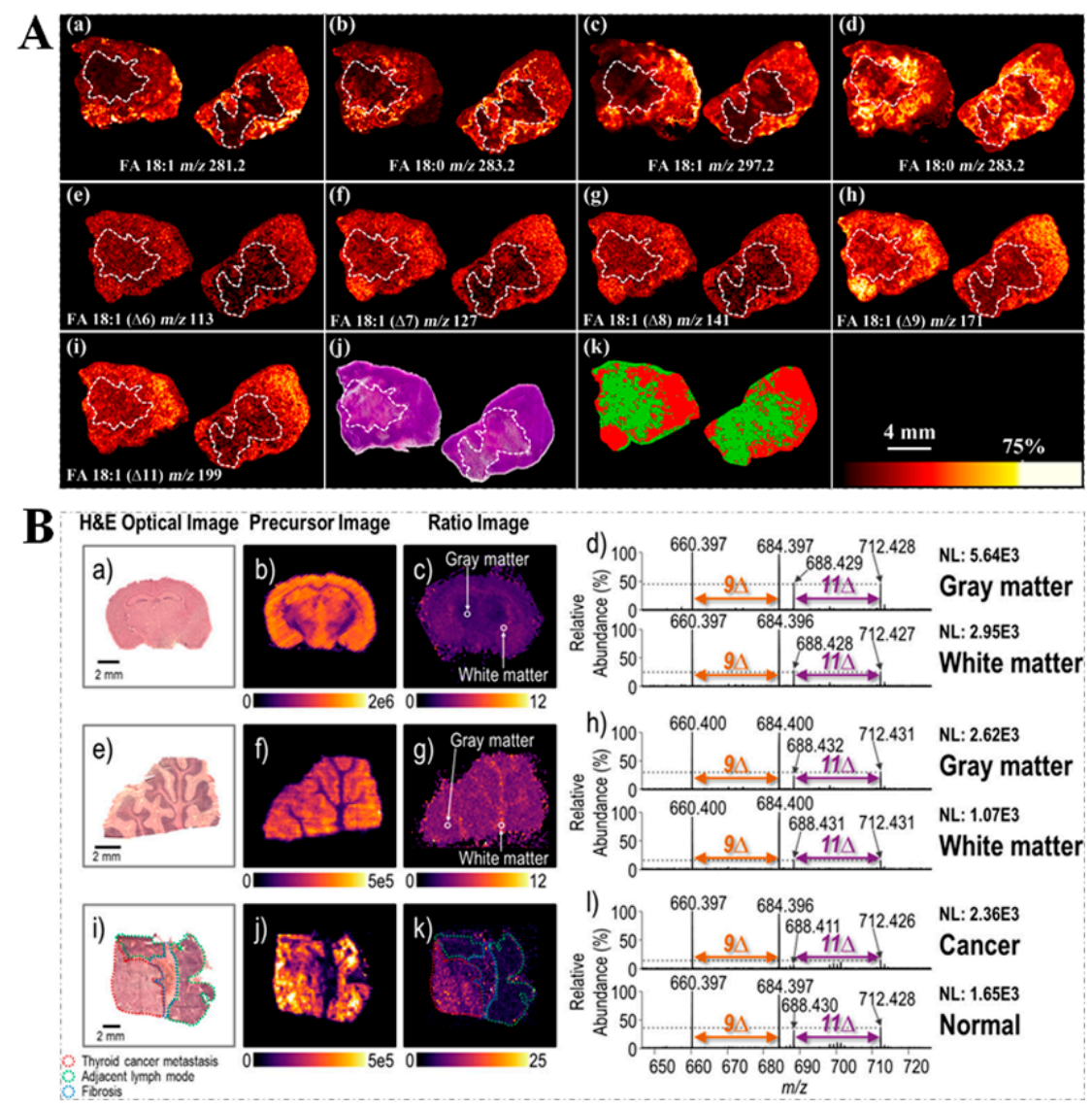

Figure 8. (A) The on-tissue PAA epoxidation strategy combined with MALDI-TOF/TOF-MS platform to map the spatial distribution of FA isomers in tissue sections. Full-MS images of (a) FA 18:1 and (b) FA 18:0 without epoxidation as well as (c) epoxy-FA 18:1 and (d) FA 18:0 after on-tissue epoxidation. MALDI-TOF/TOF-tandem MS images of (e) FA 18:1 (D6), (f) FA 18:1 (D7), (g) FA 18:1 (D8), (h) FA 18:1 (D9), (i) FA 18:1 (D11). (j) The H\&E stained histological image. (k) Segmentation pipeline analysis of the $\mathrm{MS}^{2}$ data: region rich in cancer cells (red) and region containing few cancer cells with necrosis (green). The left side tissue section was from untreated sample while the right side tissue section was from sample treated with radiation in all the images. (reproduced from Ref. [5] with permission from the Royal Society of Chemistry); (B) DESI-MS coupled with the $193 \mathrm{~nm}$ UVPD for characterization of phospholipid isomers in tissue sections. H\&E optical images of different tissue sections, including (a) mouse brain, (e) human brain, and (i) lymph node with thyroid cancer metastasis. DESI-MS ion image of $m / z 798$ in different tissue sections, including (b) mouse brain, (f) human brain, and (j) lymph node with thyroid cancer metastasis. (c) DESIUVPD ratio image of the ratio of the summed intensities of the UVPD double-bond diagnostic ions $\left(\mathrm{I}_{m / z} 660+684\right) /\left(\mathrm{I}_{m} / z 688+712\right)$, (g) DESI ratio image of the ratio of the summed intensities of the UVPD double-bond diagnostic ions $\left(\mathrm{I}_{m / z} 660+684\right) /\left(\mathrm{I}_{m} / z 688+712\right)$, and (k) DESI intensity ratio image of $\left(\mathrm{I}_{m / z} 684 / \mathrm{I}_{m / z} 712\right)$. Expanded region of UVPD mass spectra of $(\mathbf{d})$ the white and gray matter, $(\mathbf{h})$ the white and gray matter, and (1) cancerous and normal parts of tissue. (reproduced permission from Ref. [87]. Copyright (2018) American Chemical Society). 
Additionally, DESI-MS combined with $193 \mathrm{~nm}$ UVPD could map the difference in lipid isomer compositions in the tissue sections (including mouse brain tissue section, human brain tissue section, and lymph node tissue section with thyroid cancer metastasis), as well as between tissue subtypes (e.g., the white and gray matter) (Figure 8B) [87] and could directly evaluate $\mathrm{C}=\mathrm{C}$ positions in FFAs from biological tissue sections based on a charge-inversion strategy [21]. Furthermore, $m$-CPBA coupling with DESI-MS enabled a mapping of the alterations of lipid $\mathrm{C}=\mathrm{C}$ isomers on tissue sections [25], suggesting that lipid $\mathrm{C}=\mathrm{C}$ isomers were differentially expressed in distinct tissue regions and could be utilized to determine the tumor margin. In particular, when coupling the ${ }^{1} \mathrm{O}_{2}$ reaction with nano-DESI-MS, spatial localization information of lipids positional isomers was readily obtained by MS ${ }^{2}$ [ [2]. Although the appealing advantages of AIMS promote the spatial visualization of unsaturated lipid isomers within various biological tissue samples, the low sensitivity of AIMS caused by a low ionization and transmission efficiency remains the main drawback that hinders the widespread application of AIMS in lipid imaging. In this regard, more and more effective chemical derivatization approaches will need to be developed [88].

\subsection{Direct Characterization of Unsaturated Lipid Isomers in Other Samples}

With the development of MS-based lipidomic tools, the biological samples used for the advanced lipidomic studies involved, but are not limited, to tissue, biofluid, and cell samples. For instance, the elucidation of the $\mathrm{C}=\mathrm{C}$ bond position in FAs was rapidly profiled by paired offline ozonolysis with DART-MS in FAs extracts of Hawaiian Drosophila species. The results revealed that the unsaturation profile acquired from FAs extracts was helpful for the rapid differentiation of animals fed on different diets or animal species [64]. In addition, SCP-PB-nanoESI-MS was used to investigate the lipid compositions in lipid droplets of Perilla seed [47], whereas in situ ambient ionization by LTP can be used to determine C $=\mathrm{C}$ positions in unsaturated FAs and microbial fatty acid ethyl ester (FAEE) in Salmonella enterica Typhimurium INSP24 (SARA1) [54]. Additionally, on-demand electrochemical epoxidation incorporated with nanoESI-MS has been used for the analysis of complex lipids containing multiple $\mathrm{C}=\mathrm{C}$ bonds in a natural lipid extract from chicken egg yolk [58]. The established method has features including a high throughput, low sample consumption, and an in-situ derivatization and characterization of the $\mathrm{C}=\mathrm{C}$ bond, opening a new possibility for designing on-demand and specialized methods in nanoESI-MS in order to perform targeted analysis. Furthermore, the method where $\mathrm{HAuCl}_{4}$ was added into an electrospray solvent during microdroplet mass spectrometry analysis has been successfully applied to pinpoint the $\mathrm{C}=\mathrm{C}$ bond in four unsaturated fatty acids (including linoleic acid (LA), ricinoleic acid (RA), isooleic acid (IA), and nervonic acid (NA)) and two phospholipids (including 1,2-dioleoyl-sn-glycero-3-phosphocholine (DOPC) and L- $\alpha$-lysophosphatidylcholine (lysoPC)) [53]. Together, Table 1 highlights the applications of AIMS techniques in the elucidation of unsaturated lipids based on different derivatization strategies. 
Table 1. The applications of AIMS techniques in elucidation of unsaturated lipids based on different derivatization strategies.

\begin{tabular}{|c|c|c|c|c|c|c|}
\hline $\begin{array}{l}\text { Derivatization } \\
\text { Strategies }\end{array}$ & Reagents & AIMS Techniques & Sample & Analytes & LOD & Ref. \\
\hline \multirow{9}{*}{$\mathrm{PB}$} & $\begin{array}{l}\text { Acetone or acetonitrile } \\
\text { solution containing } \\
\text { benzophenone }\end{array}$ & nanoESI-MS & Single cells & FAs, SMs, and PCs & $0.1 \mathrm{pM}$ & [6] \\
\hline & \multirow{6}{*}{ Acetone } & LMJ-SSP-MS & $\begin{array}{l}\text { The sections of rat brain, lung, } \\
\text { liver, spleen, and kidney, as well } \\
\text { as in normal and diseased } \\
\text { rat tissues }\end{array}$ & FAs and PCs & $\mathrm{N} / \mathrm{A}$ & [67] \\
\hline & & \multirow{5}{*}{ nanoESI-MS } & $\begin{array}{l}\text { Rat brain tissue and rat organ } \\
\text { tissues (including kidney, liver, } \\
\text { and muscle), normal and } \\
\text { cancerous mouse breast tissues }\end{array}$ & $\begin{array}{l}\text { FAs, PEs, LPEs, LPSs, } \\
\text { PIs, LPIs, PCs, LPCs, } \\
\text { and GPs }\end{array}$ & $\mathrm{N} / \mathrm{A}$ & [16] \\
\hline & & & Rat brain, kidney, and liver tissues & $\begin{array}{l}\text { FAs, PAs, LPAs, PGs, } \\
\text { PSs, LPGs, PEs, and PIs }\end{array}$ & $\mathrm{N} / \mathrm{A}$ & [68] \\
\hline & & & $\begin{array}{l}\text { Human plasma, whole blood, and } \\
\text { cell lines }\end{array}$ & FAs & $15 \mathrm{nM}$ & [71] \\
\hline & & & Zebrafish embryos & PCs & $\mathrm{N} / \mathrm{A}$ & [69] \\
\hline & & & $\begin{array}{l}\text { Bovine blood, human blood, rat } \\
\text { blood, and homogenized mouse } \\
\text { brain samples }\end{array}$ & FAs, PEs, PSs, and PCs & $\mathrm{N} / \mathrm{A}$ & [48] \\
\hline & Benzophenone & SCP-nanoESI-MS & $\begin{array}{c}\text { Perilla seed, Zebrafish muscle, and } \\
\text { human intestinal tissue }\end{array}$ & FAs, PCs, and TAGs & $\mathrm{N} / \mathrm{A}$ & [47] \\
\hline & $\begin{array}{c}\mathrm{CH}_{3} \mathrm{OH} / \mathrm{CH}_{2} \mathrm{Cl}_{2} / \mathrm{H}_{2} \mathrm{O} \\
(v / v / v=8: 1: 1) \text { containing } \\
0.4 \mathrm{mg} / \mathrm{mL} \text { benzophenone } \\
\text { and } 0.4 \mathrm{mg} / \mathrm{mL} \\
\mathrm{NH}_{4} \mathrm{HCO}_{3}\end{array}$ & ICE-nanoESI-MS & $\begin{array}{c}\text { Human colorectal cancer tumors } \\
\text { and paired distal } \\
\text { noncancerous tissues }\end{array}$ & $\begin{array}{l}\text { PCs, LPs, SMs, FAs, PAs, } \\
\text { LPAs, PSs, LPSs, PGs, } \\
\text { LPGs, PIs, LPIs, PEs, } \\
\text { LPEs, CLs, and Cers }\end{array}$ & $\mathrm{N} / \mathrm{A}$ & [70] \\
\hline OzID & Ozone & DART-MS & Hawaiian Drosophila species & FAs & $\mathrm{N} / \mathrm{A}$ & [64] \\
\hline \multirow[t]{4}{*}{ Epoxidation } & peracetic acid & nanoESI-MS & $\begin{array}{l}\text { (HPDE/E6E7) cells and } \\
\text { (PANC-1) cells }\end{array}$ & FAs & $4.2 \mathrm{nM}$ & [5] \\
\hline & \multirow{2}{*}{$m$-СРВА } & IR-MALDESI & $\begin{array}{l}\text { Tissue sections of rat liver and } \\
\text { human bladder }\end{array}$ & FAs & $\begin{array}{l}2-4 \text { fmol per } \\
\text { laser spot }\end{array}$ & [65] \\
\hline & & DESI-MS & $\begin{array}{c}\text { Mouse kidney and metastatic } \\
\text { lung tissue }\end{array}$ & FAs and PGs & $\begin{array}{l}10 \sim 100 \\
\text { pmole }\end{array}$ & [25] \\
\hline & $\mathrm{HAuCl}_{4}$ & microdroplet-MS & Standards & $\begin{array}{l}\text { LA, RA, IA, NA, DOPC, } \\
\text { and lysoPC }\end{array}$ & $\mathrm{N} / \mathrm{A}$ & [53] \\
\hline $\begin{array}{l}\text { Electro- } \\
\text { epoxidation }\end{array}$ & $\begin{array}{l}\text { Hydrochloric acid and an } \\
\text { acetonitrile/water }\end{array}$ & \multirow{2}{*}{ nanoESI-MS } & Chicken egg yolk & PGs, PSs, and FAs & $10 \mathrm{nM}$ & [58] \\
\hline $\begin{array}{l}\text { Electro- } \\
\text { oxidation }\end{array}$ & Ir and $\mathrm{Ru}$ & & Serum & FAs & $\begin{array}{l}1.18-8.00 \\
\mu \mathrm{M}\end{array}$ & [74] \\
\hline Oxidation & ${ }^{1} \mathrm{O}_{2}$ & nano-DESI-MS & $\begin{array}{l}\text { Rat brain, mouse uterine, and } \\
\text { gastrocnemius muscle tissue }\end{array}$ & FAs, LPEs, PEs, and PCs & $\mathrm{N} / \mathrm{A}$ & [2] \\
\hline \multirow[t]{2}{*}{ UVPD } & \multirow[t]{2}{*}{$193 \mathrm{~nm}$} & \multirow[t]{2}{*}{ DESI-MS } & $\begin{array}{l}\text { Mouse brain and kidney tissues, } \\
\text { pancreas, kidney, lung, fallopian, } \\
\text { ovarian tissue, and } \\
\text { endometrial tissue }\end{array}$ & $\mathrm{PCs}$ & $\sim 500 \mathrm{nM}$ & [87] \\
\hline & & & $\begin{array}{l}\text { Mouse brain tissue, human } \\
\text { ovarian tumor tissue, and breast } \\
\text { cancer tissue }\end{array}$ & FAs & $\mathrm{N} / \mathrm{A}$ & [21] \\
\hline \multirow{4}{*}{ LTP } & Pure helium & \multirow[b]{2}{*}{ nanoESI-MS } & Human plasma & FAs & $0.07 \mu \mathrm{M}$ & [72] \\
\hline & Oxygen & & Bovine liver polar extract & $\begin{array}{l}\text { PCs, PAs, PEs, PGs, } \\
\text { and PIs }\end{array}$ & $\mathrm{N} / \mathrm{A}$ & [73] \\
\hline & $\begin{array}{l}\text { Reactive oxygen species in } \\
\text { the plasma }\end{array}$ & \multirow{2}{*}{ LTP-MS } & $\begin{array}{c}\text { Human, Equine, and Fetal } \\
\text { Bovine Serums }\end{array}$ & FAs & $0.1 \mu \mathrm{M}$ & [55] \\
\hline & Ozone & & $\begin{array}{l}\text { Salmonella enterica typhimurium } \\
\text { INSP24 (SARA1) }\end{array}$ & FAs and FAEE & $\mathrm{N} / \mathrm{A}$ & [54] \\
\hline
\end{tabular}

N/A represents information not available.

\section{Conclusions and Future Directions}

Profiling the complete molecular composition of lipidome is helpful for revealing the potential pathways and mechanism in lipid metabolism. Compared with traditional chromatographic separation coupled with MS, AIMS offers simplicity and a higher throughput for lipid structural elucidation. To date, a series of derivatization methods (including 
the PB reaction, OzID, epoxidation reaction, ${ }^{1} \mathrm{O}_{2}$, UVPD, and plasma/electrochemicalinduced epoxidation) in conjunction with various AIMS techniques (e.g., nanoESI-MS, DESI-MS/nano-DESI-MS, IR-MALDESI, and LTP-MS) have been successfully implemented for the direct structural characterization of lipid isomers from different biological samples (e.g., tissue, biofluids, and cell samples), showing great potential in lipid structural elucidation, both in laboratory research and clinical molecular diagnosis. Even though the field of lipidomics has been greatly advanced by AIMS, there remains challenges related to comprehensive lipidome identification and structural characterization.

First, owing to the highly complexity of the lipidome, besides the investigation of $\mathrm{C}=\mathrm{C}$ positions, many more efforts are still needed for the elucidation of sn-positions, branched chain isomers, and the spatial distribution of broad types of unsaturated lipids. Additionally, a method that could be used for in situ and in vivo monitoring and offering an absolute quantitation of unsaturated lipid changes with high precision is still lacking. Current AIMS experiments have been carried out under ambient conditions, which are susceptible to interference from the environment. Hence, the reproducibility of the quantitative and qualitative analysis of unsaturated lipids in complex biological samples by AIMS need to be further improved. This might be improved either by the addition of internal standards or by using a commercial and high precision AIMS device, but many more efforts need to be made on method automation, hardware integration, and software development. Moreover, it is necessary to develop advanced computational tools, including automated software and machine learning algorithms, to facilitate the analysis of large datasets collected by different AIMS techniques coupled with derivatization methods. Ultimately, orthogonal and parallel biological studies need to be conducted to fully understand the functional implications caused by lipid structure heterogeneity and alteration.

Author Contributions: Writing—original draft preparation, H.L., H.Z. and L.L.; writing—review and editing, H.L., S.X. and L.L.; supervision, L.L. All authors have read and agreed to the published version of the manuscript.

Funding: This work was funded in part by NIH (R01DK071801 and P01CA250972) and the United States Department of Agriculture (grant number 2018-67001-28266). LL would like to acknowledge NIH grant support RF1AG052324, NCRRS10RR029531, and S10OD025084, a Pancreas Cancer Pilot grant from the University of Wisconsin Carbone Cancer Center (233-AAI9632), as well as a Vilas Distinguished Achievement Professorship and Charles Melbourne Johnson Distinguished Chair Professorship with funding provided by the Wisconsin Alumni Research Foundation and University of Wisconsin-Madison School of Pharmacy.

Conflicts of Interest: There is no conflict of interest to declare.

\begin{abstract}
Abbreviations
Ambient ionization mass spectrometry (AIMS), Paternò-Büchi (PB) reaction, ozone-induced dissociation (OzID), carbon-carbon double bond ( $\mathrm{C}=\mathrm{C})$, type II diabetes (T2D), mass spectrometry (MS), tandem mass spectrometry (MS/MS), collision-induced desorption (CID), electron-induced dissociation (EID), ultraviolet photodissociation (UVPD), meta-chloroperoxybenzoic aid ( $m$-CPBA) epoxidation, peracetic acid (PAA) epoxidation, liquid chromatography (LC), desorption electrospray ionization mass spectrometry (DESI-MS), rapid evaporative ionization mass spectrometry (REIMS), internal extractive electrospray ionization mass spectrometry (iEESI-MS), atmospheric pressure matrix-assisted laser/desorption ionization mass spectrometry (AP-MALDI-MS), matrixassisted laser desorption/ionization mass spectrometry (MALDI-MS), PB reaction coupling to tandem MS (PB-MS/MS), 2-acetylpyridine (2-AP), 2' '4' $4^{\prime} 6^{\prime}$-trifluoroacetophenone (triFAP), N,N-diethyl-1,2ethanediamine (DEEA), free fatty acids (FFAs), polymer coating transfer enrichment (PCTE), PB reaction with surface-coated probe nanoESI-MS (SCP-PB-nanoESI-MS), matrix-assisted laser desorption/ionization time-of-fight/time-of-fight MS (MALDI-TOF/TOF-MS), fatty acids (FAs), limit of detections (LODs), relative standard deviations (RSDs), chloroauric acid ( $\left.\mathrm{HAuCl}_{4}\right)$, low-temperature plasma (LTP), paper-based analytical devices (PADs), singlet oxygen $\left({ }^{1} \mathrm{O}_{2}\right)$, lipid hydroperoxides (LOOHs), mass spectrometry imaging (MSI), nanospray desorption electrospray ionization mass
\end{abstract}


spectrometry (nano-DESI-MS), ion mobility-mass spectrometry (IM-MS), high-performance liquid chromatography-tandem mass spectrometry (HPLC-MS/MS), glycerophospholipids (GPs), liquid microjunction surface sampling probe (LMJ-SSP), phosphatidylserines (PSs), phosphatidylglycerols (PGs), phosphatidylinositols (PIs), phosphatidylethanolamines (PEs), phosphatidic acids (PAs), lysoPAs (LPAs) and lyso-PGs (LPGs), nonalcoholic fatty liver disease (NAFLD), infrared matrix-assisted laser desorption electrospray ionization (IR-MALDESI), in-capillary extraction nanoelectrospray ionization mass spectrometry (ICE-nanoESI-MS), phosphatidylcholines (PCs), phosphatidylinositols (PIs), neutral loss scan (NLS), point-of-care (POC), HPV16-E6E7 immortalized human pancreatic duct epithelial (HPDE/E6E7) cells, pancreatic cancer cells (PANC-1), single cell mass spectrometry (SCMS), mass spectrometry imaging (MSI), matrix-assisted laser desorption ionization mass spectrometry imaging (MAL-DI-MSI), quadrupole time-of-flight (Q-TOF), N,N,N-trimethyl-2-(piperazin-1-yl)ethan1-aminium iodide (TMPA), fatty acid ethyl ester (FAEE), Salmonella enterica Typhimurium INSP24 (SARA1), lysophosphatidylcholines (LPCs), sphingomyelins (SMs), linoleic acid (LA), ricinoleic acid (RA), isooleic acid (IA), nervonic acid (NA), 1,2-dioleoyl-sn-glycero-3-phosphocholine (DOPC), L- $\alpha$-lysophosphatidylcholine (lysoPC), lysophosphatidylserines (LPSs), lysophosphatidylinositols (LPIs), lysophosphoethanolamines (LPEs), cardiolipin (CLs), and ceramides (Cers).

\section{References}

1. Klein, D.R.; Blevins, M.S.; Macias, L.A.; Douglass, M.V.; Trent, M.S.; Brodbelt, J.S. Localization of Double Bonds in Bacterial Glycerophospholipids Using 193 nm Ultraviolet Photodissociation in the Negative Mode. Anal. Chem. 2020, 92, 5986-5993. [CrossRef] [PubMed]

2. Unsihuay, D.; Su, P.; Hu, H.; Qiu, J.; Kuang, S.; Li, Y.; Sun, X.; Dey, S.K.; Laskin, J. Imaging and Analysis of Isomeric Unsaturated Lipids through Online Photochemical Derivatization of Carbon-Carbon Double Bonds *. Angew Chem. Int. Ed. Engl. 2021, 60, 7559-7563. [CrossRef] [PubMed]

3. Feng, G.F.; Hao, Y.H.; Wu, L.; Chen, S.M. A visible-light activated [2 + 2] cycloaddition reaction enables pinpointing carbon-carbon double bonds in lipids. Chem. Sci. 2020, 11, 7244-7251. [CrossRef] [PubMed]

4. Xu, T.; Hu, C.; Xuan, Q.; Xu, G. Recent advances in analytical strategies for mass spectrometry-based lipidomics. Anal Chim Acta 2020, 1137, 156-169. [CrossRef]

5. Zhang, H.; Xu, M.; Shi, X.; Liu, Y.; Li, Z.; Jagodinsky, J.C.; Ma, M.; Welham, N.V.; Morris, Z.S.; Li, L. Quantification and molecular imaging of fatty acid isomers from complex biological samples by mass spectrometry. Chem. Sci. 2021, 12, 8115-8122. [CrossRef]

6. Zhu, Y.; Wang, W.; Yang, Z. Combining Mass Spectrometry with Paternò-Büchi Reaction to Determine Double-Bond Positions in Lipids at the Single-Cell Level. Anal. Chem. 2020, 92, 11380-11387. [CrossRef]

7. Zhang, W.P.; Shang, B.; Ouyang, Z.; Xia, Y. Enhanced Phospholipid Isomer Analysis by Online Photochemical Derivatization and RPLC-MS. Anal. Chem. 2020, 92, 6719-6726. [CrossRef]

8. Zhang, W.P.; Zhang, D.H.; Chen, Q.H.; Wu, J.H.; Ouyang, Z.; Xia, Y. Online photochemical derivatization enables comprehensive mass spectrometric analysis of unsaturated phospholipid isomers. Nat. Commun. 2019, 10, 79. [CrossRef]

9. Rohrig, F.; Schulze, A. The multifaceted roles of fatty acid synthesis in cancer. Nat. Rev. Cancer 2016, 16, 732-749. [CrossRef]

10. Bazinet, R.P.; Laye, S. Polyunsaturated fatty acids and their metabolites in brain function and disease. Nat. Rev. Neurosci. 2014, 15, 771-785. [CrossRef]

11. Cao, W.B.; Cheng, S.M.; Yang, J.; Feng, J.X.; Zhang, W.P.; Li, Z.S.; Chen, Q.H.; Xia, Y.; Ouyang, Z.; Ma, X.X. Large-scale lipid analysis with $\mathrm{C}=\mathrm{C}$ location and sn-position isomer resolving power. Nat. Commun. 2020, 11, 375. [CrossRef]

12. Stinson, C.A.; Xia, Y. A method of coupling the Paterno-Buchi reaction with direct infusion ESI-MS/MS for locating the C=C bond in glycerophospholipids. Analyst 2016, 141, 3696-3704. [CrossRef]

13. Zhang, H.; Chingin, K.; Li, J.; Lu, H.; Huang, K.; Chen, H. Selective Enrichment of Phosphopeptides and Phospholipids from Biological Matrixes on $\mathrm{TiO}_{2}$ Nanowire Arrays for Direct Molecular Characterization by Internal Extractive Electrospray Ionization Mass Spectrometry. Anal. Chem. 2018, 90, 12101-12107. [CrossRef]

14. Zhang, H.; Lu, H.; Huang, K.; Li, J.; Wei, F.; Liu, A.; Chingin, K.; Chen, H. Selective detection of phospholipids in human blood plasma and single cells for cancer differentiation using dispersed solid-phase microextraction combined with extractive electrospray ionization mass spectrometry. Analyst 2020, 145, 7330-7339. [CrossRef]

15. Wang, J.; Wang, C.; Han, X. Tutorial on lipidomics. Anal Chim Acta 2019, 1061, 28-41. [CrossRef]

16. Ma, X.X.; Chong, L.; Tian, R.; Shi, R.Y.; Hu, T.Y.; Ouyang, Z.; Xia, Y. Identification and quantitation of lipid C=C location isomers: A shotgun lipidomics approach enabled by photochemical reaction. Proc. Natl. Acad. Sci. USA 2016, 113, 2573-2578. [CrossRef]

17. Porta Siegel, T.; Ekroos, K.; Ellis, S.R. Reshaping Lipid Biochemistry by Pushing Barriers in Structural Lipidomics. Angew. Chem. Int. Ed. Engl. 2019, 58, 6492-6501. [CrossRef]

18. Paine, M.R.L.; Poad, B.L.J.; Eijkel, G.B.; Marshall, D.L.; Blanksby, S.J.; Heeren, R.M.A.; Ellis, S.R. Mass Spectrometry Imaging with Isomeric Resolution Enabled by Ozone-Induced Dissociation. Angew. Chem. Int. Ed. 2018, 57, 10530-10534. [CrossRef] 
19. Knowles, S.L.; Vu, N.; Todd, D.A.; Raja, H.A.; Rokas, A.; Zhang, Q.B.; Oberlies, N.H. Orthogonal Method for Double-Bond Placement via Ozone-Induced Dissociation Mass Spectrometry (OzID-MS). J. Nat. Prod. 2019, 82, 3421-3431. [CrossRef]

20. Jones, J.W.; Thompson, C.J.; Carter, C.L.; Kane, M.A. Electron-induced dissociation (EID) for structure characterization of glycerophosphatidylcholine: Determination of double-bond positions and localization of acyl chains. J. Mass Spectrom. 2015, 50, 1327-1339. [CrossRef]

21. Feider, C.L.; Macias, L.A.; Brodbelt, J.S.; Eberlin, L.S. Double Bond Characterization of Free Fatty Acids Directly from Biological Tissues by Ultraviolet Photodissociation. Anal. Chem. 2020, 92, 8386-8395. [CrossRef]

22. Xie, X.B.; Xia, Y. Analysis of Conjugated Fatty Acid Isomers by the Paterno-Buchi Reaction and Trapped Ion Mobility Mass Spectrometry. Anal. Chem. 2019, 91, 7173-7180. [CrossRef]

23. Ma, X.X.; Xia, Y. Pinpointing Double Bonds in Lipids by Paterno-Buchi Reactions and Mass Spectrometry. Angew. Chem. Int. Ed. 2014, 53, 2592-2596. [CrossRef]

24. Feng, Y.; Chen, B.; Yu, Q.; Li, L. Identification of Double Bond Position Isomers in Unsaturated Lipids by m-CPBA Epoxidation and Mass Spectrometry Fragmentation. Anal. Chem. 2019, 91, 1791-1795. [CrossRef]

25. Kuo, T.-H.; Chung, H.-H.; Chang, H.-Y.; Lin, C.-W.; Wang, M.-Y.; Shen, T.-L.; Hsu, C.-C. Deep Lipidomics and Molecular Imaging of Unsaturated Lipid Isomers: A Universal Strategy Initiated by mCPBA Epoxidation. Anal. Chem. 2019, 91, 11905-11915. [CrossRef]

26. Xie, X.B.; Zhao, J.; Lin, M.; Zhang, J.L.; Xia, Y. Profiling of Cholesteryl Esters by Coupling Charge-Tagging Paterno-Buchi Reaction and Liquid Chromatography-Mass Spectrometry. Anal. Chem. 2020, 92, 8487-8496. [CrossRef]

27. Jeck, V.; Korf, A.; Vosse, C.; Hayen, H. Localization of double-bond positions in lipids by tandem mass spectrometry succeeding high-performance liquid chromatography with post-column derivatization. Rapid Commun. Mass Spectrom. 2019, 33, 86-94. [CrossRef]

28. Hakova, E.; Vrkoslav, V.; Mikova, R.; Schwarzova-Peckova, K.; Bosakova, Z.; Cvacka, J. Localization of double bonds in triacylglycerols using high-performance liquid chromatography/atmospheric pressure chemical ionization ion-trap mass spectrometry. Anal. Bioanal. Chem. 2015, 407, 5175-5188. [CrossRef]

29. Lu, H.; Zhang, H.; Chingin, K.; Xiong, J.; Fang, X.; Chen, H. Ambient mass spectrometry for food science and industry. Trac-Trend Anal. Chem. 2018, 107, 99-115. [CrossRef]

30. Cooks, R.G.; Ouyang, Z.; Takats, Z.; Wiseman, J.M. Ambient mass spectrometry. Science 2006, 311, 1566-1570. [CrossRef]

31. Balog, J.; Sasi-Szabo, L.; Kinross, J.; Lewis, M.R.; Muirhead, L.J.; Veselkov, K.; Mirnezami, R.; Dezso, B.; Damjanovich, L.; Darzi, A.; et al. Intraoperative Tissue Identification Using Rapid Evaporative Ionization Mass Spectrometry. Sci. Transl. Med. 2013, 5, 194ra93. [CrossRef] [PubMed]

32. Zhang, J.L.; Rector, J.; Lin, J.Q.; Young, J.H.; Sans, M.; Katta, N.; Giese, N.; Yu, W.D.; Nagi, C.; Suliburk, J.; et al. Nondestructive tissue analysis for ex vivo and in vivo cancer diagnosis using a handheld mass spectrometry system. Sci. Transl. Med. 2017, 9. [CrossRef] [PubMed]

33. Lu, H.; Zhang, H.; Chingin, K.; Wei, Y.; Xu, J.; Ke, M.; Huang, K.; Feng, S.; Chen, H. Sequential Detection of Lipids, Metabolites, and Proteins in One Tissue for Improved Cancer Differentiation Accuracy. Anal. Chem. 2019, 91, 10532-10540. [CrossRef] [PubMed]

34. Lu, H.; Zhang, H.; Xiao, Y.; Chingin, K.; Dai, C.; Wei, F.; Wang, N.; Frankevich, V.; Chagovets, V.; Zhou, F.; et al. Comparative study of alterations in phospholipid profiles upon liver cancer in humans and mice. Analyst 2020, 145, 6470-6477. [CrossRef]

35. Jackson, S.N.; Muller, L.; Roux, A.; Oktem, B.; Moskovets, E.; Doroshenko, V.M.; Woods, A.S. AP-MALDI Mass Spectrometry Imaging of Gangliosides Using 2,6-Dihydroxyacetophenone. J. Am. Soc. Mass Spectrom. 2018, 29, 1463-1472. [CrossRef]

36. Abdelhamid, H.N.; Bhaisare, M.L.; Wu, H.F. Ceria nanocubic-ultrasonication assisted dispersive liquid-liquid microextraction coupled with matrix assisted laser desorption/ionization mass spectrometry for pathogenic bacteria analysis. Talanta 2014, 120, 208-217. [CrossRef]

37. Hua, P.Y.; Manikandan, M.; Abdelhamid, H.N.; Wu, H.F. Graphene nanoflakes as an efficient ionizing matrix for MALDI-MS based lipidomics of cancer cells and cancer stem cells. J. Mater Chem. B 2014, 2, 7334-7343. [CrossRef]

38. Keller, C.; Maeda, J.; Jayaraman, D.; Chakraborty, S.; Sussman, M.R.; Harris, J.M.; Ane, J.M.; Li, L. Comparison of Vacuum MALDI and AP-MALDI Platforms for the Mass Spectrometry Imaging of Metabolites Involved in Salt Stress in Medicago truncatula. Front. Plant Sci. 2018, 9, 1238. [CrossRef]

39. Chen, B.; OuYang, C.; Tian, Z.; Xu, M.; Li, L. A high resolution atmospheric pressure matrix-assisted laser desorption/ionizationquadrupole-orbitrap MS platform enables in situ analysis of biomolecules by multi-mode ionization and acquisition. Anal. Chim. Acta 2018, 1007, 16-25. [CrossRef]

40. Caleb Bagley, M.; Garrard, K.P.; Muddiman, D.C. The development and application of matrix assisted laser desorption electrospray ionization: The teenage years. Mass Spectrom. Rev. 2021. [CrossRef]

41. Adam, W.; Peters, K.; Peters, E.M.; Stegmann, V.R. Hydroxy-Directed Regio- and Diastereoselective [2 + 2] Photocycloaddition (Paternò-Büchi Reaction) of Benzophenone to Chiral Allylic Alcohols. J. Am. Chem. Soc. 2000, 122, 2958-2959. [CrossRef]

42. Waldchen, F.; Spengler, B.; Heiles, S. Reactive Matrix-Assisted Laser Desorption/Ionization Mass Spectrometry Imaging Using an Intrinsically Photoreactive Paterno-Buchi Matrix for Double-Bond Localization in Isomeric Phospholipids. J. Am. Chem. Soc. 2019, 141, 11816-11820. [CrossRef] 
43. Chonglo, L.; Tian, R.; Shi, R.Y.; Ouyang, Z.; Xia, Y. Coupling the Paterno-Buchi (PB) Reaction With Mass Spectrometry to Study Unsaturated Fatty Acids in Mouse Model of Multiple Sclerosis. Front. Chem. 2019, 7. [CrossRef]

44. Xu, T.F.; Pi, Z.F.; Song, F.R.; Liu, S.; Liu, Z.Q. Benzophenone used as the photochemical reagent for pinpointing C=C locations in unsaturated lipids through shotgun and liquid chromatography-mass spectrometry approaches. Anal. Chim. Acta 2018, 1028, 32-44. [CrossRef]

45. Zhao, J.; Xie, X.; Lin, Q.; Ma, X.; Su, P.; Xia, Y. Next-Generation Paterno-Buchi Reagents for Lipid Analysis by Mass Spectrometry. Anal. Chem. 2020, 92, 13470-13477. [CrossRef]

46. Xu, S.L.; Wu, B.F.; Oresic, M.; Xie, Y.; Yao, P.; Wu, Z.Y.; Lv, X.; Chen, H.; Wei, F. Double Derivatization Strategy for High-Sensitivity and High- Coverage Localization of Double Bonds in Free Fatty Acids by Mass Spectrometry. Anal. Chem. 2020, 92, 6446-6455. [CrossRef]

47. Deng, J.; Yang, Y.; Liu, Y.; Fang, L.; Lin, L.; Luan, T. Coupling Paterno-Buchi Reaction with Surface-Coated Probe Nanoelectrospray Ionization Mass Spectrometry for In Vivo and Microscale Profiling of Lipid C horizontal lineC Location Isomers in Complex Biological Tissues. Anal. Chem. 2019, 91, 4592-4599. [CrossRef]

48. Zhang, W.P.; Chiang, S.; Li, Z.S.; Chen, Q.H.; Xia, Y.; Ouyang, Z. A Polymer Coating Transfer Enrichment Method for Direct Mass Spectrometry Analysis of Lipids in Biofluid Samples. Angew. Chem. Int. Ed. 2019, 58, 6064-6069. [CrossRef]

49. Thomas, M.C.; Mitchell, T.W.; Harman, D.G.; Deeley, J.M.; Nealon, J.R.; Blanksby, S.J. Ozone-Induced Dissociation: Elucidation of Double Bond Position within Mass-Selected Lipid Ions. Anal. Chem. 2008, 80, 303-311. [CrossRef]

50. Klein, D.R.; Brodbelt, J.S. Structural Characterization of Phosphatidylcholines Using 193 nm Ultraviolet Photodissociation Mass Spectrometry. Anal. Chem. 2017, 89, 1516-1522. [CrossRef]

51. Williams, P.E.; Klein, D.R.; Greer, S.M.; Brodbelt, J.S. Pinpointing Double Bond and sn-Positions in Glycerophospholipids via Hybrid $193 \mathrm{~nm}$ Ultraviolet Photodissociation (UVPD) Mass Spectrometry. J. Am. Chem. Soc. 2017, 139, 15681-15690. [CrossRef]

52. Brodbelt, J.S.; Morrison, L.J.; Santos, I. Ultraviolet Photodissociation Mass Spectrometry for Analysis of Biological Molecules. Chem. Rev. 2020, 120, 3328-3380. [CrossRef]

53. Luo, K.; Chen, H.; Zare, R.N. Location of carbon-carbon double bonds in unsaturated lipids using microdroplet mass spectrometry. Analyst 2021, 146, 2550-2558. [CrossRef]

54. Zhang, J.I.; Tao, W.A.; Cooks, R.G. Facile determination of double bond position in unsaturated fatty acids and esters by low temperature plasma ionization mass spectrometry. Anal. Chem. 2011, 83, 4738-4744. [CrossRef] [PubMed]

55. Zhao, X.; Zhao, Y.; Zhang, L.; Ma, X.; Zhang, S.; Zhang, X. Rapid Analysis of Unsaturated Fatty Acids on Paper-Based Analytical Devices via Online Epoxidation and Ambient Mass Spectrometry. Anal. Chem. 2018, 90, 2070-2078. [CrossRef] [PubMed]

56. Steyer, D.J.; Kennedy, R.T. High-Throughput Nanoelectrospray Ionization-Mass Spectrometry Analysis of Microfluidic Droplet Samples. Anal. Chem. 2019, 91, 6645-6651. [CrossRef] [PubMed]

57. Domon, B.; Aebersold, R. Review-Mass spectrometry and protein analysis. Science 2006, 312, 212-217. [CrossRef] [PubMed]

58. Tang, S.L.; Cheng, H.Y.; Yan, X. On-Demand Electrochemical Epoxidation in Nano-Electrospray Ionization Mass Spectrometry to Locate Carbon-Carbon Double Bonds. Angew. Chem. Int. Ed. 2020, 59, 209-214. [CrossRef]

59. Zhang, X.; Wang, W.; Zare, R.N.; Min, Q. Peptide and protein assays using customizable bio-affinity arrays combined with ambient ionization mass spectrometry. Chem. Sci. 2021, 12, 10810-10816. [CrossRef]

60. Bergman, H.M.; Lanekoff, I. Profiling and quantifying endogenous molecules in single cells using nano-DESI MS. Analyst 2017, 142, 3639-3647. [CrossRef]

61. Kirschbaum, C.; Greis, K.; Lettow, M.; Gewinner, S.; Schollkopf, W.; Meijer, G.; von Helden, G.; Pagel, K. Non-covalent double bond sensors for gas-phase infrared spectroscopy of unsaturated fatty acids. Ana. Bioanal. Chem. 2021, 413, 3643-3653. [CrossRef]

62. Barrientos, R.C.; Vu, N.; Zhang, Q.B. Structural Analysis of Unsaturated Glycosphingolipids Using Shotgun Ozone-Induced Dissociation Mass Spectrometry. J. Am. Soc. Mass Spectrom. 2017, 28, 2330-2343. [CrossRef]

63. Vu, N.; Brown, J.; Giles, K.; Zhang, Q.B. Ozone-induced dissociation on a traveling wave high-resolution mass spectrometer for determination of double-bond position in lipids. Rapid Commun. Mass Spectrom. 2017, 31, 1415-1423. [CrossRef]

64. Cetraro, N.; Cody, R.B.; Yew, J.Y. Carbon-carbon double bond position elucidation in fatty acids using ozone-coupled direct analysis in real time mass spectrometry. Analyst 2019, 144, 5848-5855. [CrossRef]

65. Tu, A.; Garrard, K.P.; Said, N.; Muddiman, D.C. In situ Detection of Fatty Acid C=C Positional Isomers by Coupling On-tissue mCPBA Epoxidation with IR-MALDESI Mass Spectrometry. Rapid Commun. Mass Spectrom. 2021, e9119. [CrossRef]

66. Lu, H.; Zhang, H.; Wei, Y.; Chen, H. Ambient mass spectrometry for the molecular diagnosis of lung cancer. Analyst 2020, 145, 313-320. [CrossRef]

67. Tang, F.; Guo, C.G.; Ma, X.X.; Zhang, J.; Su, Y.; Tian, R.; Shi, R.Y.; Xia, Y.; Wang, X.H.; Ouyang, Z. Rapid In Situ Profiling of Lipid C $=$ C Location Isomers in Tissue Using Ambient Mass Spectrometry with Photochemical Reactions. Anal. Chem. 2018, 90, 5612-5619. [CrossRef]

68. Su, Y.; Ma, X.X.; Page, J.; Shi, R.Y.; Xia, Y.; Ouyang, Z. Mapping lipid C=C location isomers in organ tissues by Coupling photochemical derivatization and rapid extractive mass spectrometry. Int. J. Mass Spectrom. 2019, 445, 116206. [CrossRef]

69. Zhao, X.; Chen, J.; Zhang, W.Y.; Yang, C.D.; Ma, X.X.; Zhang, S.C.; Zhang, X.R. Lipid Alterations during Zebrafish Embryogenesis Revealed by Dynamic Mass Spectrometry Profiling with C=C Specificity. J. Am. Soc. Mass Spectrom. 2019, 30, 2646-2654. [CrossRef] 
70. Deng, J.; Yang, Y.; Zeng, Z.; Xiao, X.; Li, J.; Luan, T. Discovery of Potential Lipid Biomarkers for Human Colorectal Cancer by In-Capillary Extraction Nanoelectrospray Ionization Mass Spectrometry. Anal. Chem. 2021, 93, 13089-13098. [CrossRef]

71. Ma, X.X.; Zhao, X.; Li, J.J.; Zhang, W.P.; Cheng, J.X.; Ouyang, Z.; Xia, Y. Photochemical Tagging for Quantitation of Unsaturated Fatty Acids by Mass Spectrometry. Anal. Chem. 2016, 88, 8931-8935. [CrossRef]

72. Zhao, Y.Y.; Zhao, H.S.; Zhao, X.; Jia, J.; Ma, Q.; Zhang, S.C.; Zhang, X.R.; Chiba, H.; Hui, S.P.; Ma, X.X. Identification and Quantitation of $\mathrm{C}=\mathrm{C}$ Location Isomers of Unsaturated Fatty Acids by Epoxidation Reaction and Tandem Mass Spectrometry. Anal. Chem. 2017, 89, 10270-10278. [CrossRef]

73. Cao, W.B.; Ma, X.X.; Li, Z.S.; Zhou, X.Y.; Ouyang, Z. Locating Carbon-Carbon Double Bonds in Unsaturated Phospholipids by Epoxidation Reaction and Tandem Mass Spectrometry. Anal. Chem. 2018, 90, 10286-10292. [CrossRef]

74. Chintalapudi, K.; Badu-Tawiah, A.K. An integrated electrocatalytic nESI-MS platform for quantification of fatty acid isomers directly from untreated biofluids. Chem. Sci. 2020, 11, 9891-9897. [CrossRef]

75. Gaston, R.; Maria Eugenia, P.; Das, U.N.; Eynard, A.R. Polyunsaturated Fatty Acids Differentially Modulate Cell Proliferation and Endocannabinoid System in Two Human Cancer Lines. Arch. Med. Res. 2017, 48, 46-54. [CrossRef]

76. Nakkarach, A.; Foo, H.L.; Song, A.A.; Mutalib, N.E.A.; Nitisinprasert, S.; Withayagiat, U. Anti-cancer and anti-inflammatory effects elicited by short chain fatty acids produced by Escherichia coli isolated from healthy human gut microbiota. Microb. Cell Fact. 2021, 20, 36. [CrossRef]

77. Hu, R.; Li, Y.; Yang, Y.; Liu, M. Mass spectrometry-based strategies for single-cell metabolomics. Mass Spectrom. Rev. 2021. [CrossRef]

78. Wu, C.; Dill, A.L.; Eberlin, L.S.; Cooks, R.G.; Ifa, D.R. Mass spectrometry imaging under ambient conditions. Mass Spectrom. Rev. 2013, 32, 218-243. [CrossRef]

79. Handberg, E.; Chingin, K.; Wang, N.; Dai, X.; Chen, H. Mass spectrometry imaging for visualizing organic analytes in food. Mass Spectrom. Rev. 2015, 34, 641-658. [CrossRef]

80. Gemperline, E.; Chen, B.; Li, L. Challenges and recent advances in mass spectrometric imaging of neurotransmitters. Bioanalysis 2014, 6, 525-540. [CrossRef]

81. Johnson, J.; Sharick, J.T.; Skala, M.C.; Li, L. Sample preparation strategies for high-throughput mass spectrometry imaging of primary tumor organoids. J. Mass Spectrom. 2020, 55, e4452. [CrossRef] [PubMed]

82. Marshall, D.L.; Criscuolo, A.; Young, R.S.E.; Poad, B.L.J.; Zeller, M.; Reid, G.E.; Mitchell, T.W.; Blanksby, S.J. Mapping Unsaturation in Human Plasma Lipids by Data-Independent Ozone-Induced Dissociation. J. Am. Soc. Mass Spectrom. 2019, 30, 1621-1630. [CrossRef] [PubMed]

83. Bednarik, A.; Bolsker, S.; Soltwisch, J.; Dreisewerd, K. An On-Tissue Paterno-Buchi Reaction for Localization of Carbon-Carbon Double Bonds in Phospholipids and Glycolipids by Matrix-Assisted Laser-Desorption-Ionization Mass-Spectrometry Imaging. Angew. Chem. Int. Ed. 2018, 57, 12092-12096. [CrossRef] [PubMed]

84. Claes, B.S.R.; Bowman, A.P.; Poad, B.L.J.; Young, R.S.E.; Heeren, R.M.A.; Blanksby, S.J.; Ellis, S.R. Mass Spectrometry Imaging of Lipids with Isomer Resolution Using High-Pressure Ozone-Induced Dissociation. Anal. Chem. 2021, 93, 9826-9834. [CrossRef]

85. Bednarik, A.; Preisler, J.; Bezdekova, D.; Machalkova, M.; Hendrych, M.; Navratilova, J.; Knopfova, L.; Moskovets, E.; Soltwisch, J.; Dreisewerd, K. Ozonization of Tissue Sections for MALDI MS Imaging of Carbon-Carbon Double Bond Positional Isomers of Phospholipids. Anal. Chem. 2020, 92, 6245-6250. [CrossRef]

86. Sun, C.; Liu, W.; Geng, Y.; Wang, X. On-Tissue Derivatization Strategy for Mass Spectrometry Imaging of Carboxyl-Containing Metabolites in Biological Tissues. Anal. Chem. 2020, 92, 12126-12131. [CrossRef]

87. Klein, D.R.; Feider, C.L.; Garza, K.Y.; Lin, J.Q.; Eberlin, L.S.; Brodbelt, J.S. Desorption Electrospray Ionization Coupled with Ultraviolet Photodissociation for Characterization of Phospholipid Isomers in Tissue Sections. Anal. Chem. 2018, 90, 10100-10104. [CrossRef]

88. Xia, F.; Wan, J.B. Chemical derivatization strategy for mass spectrometry-based lipidomics. Mass Spectrom. Rev. 2021, e21729. [CrossRef] 